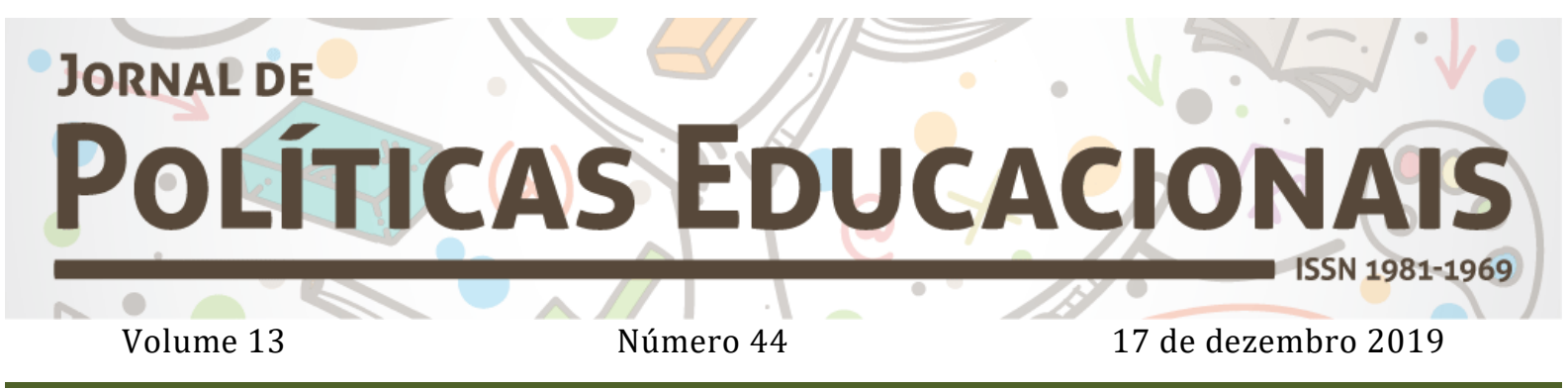

\title{
Formação de professores para a qualidade na educação básica: contextos que conduziram à implementação do Parfor
}

\author{
Teacher training for quality in basic education: contexts that led to the \\ implementation of Parfor
}

\section{Formación de docentes para la calidad en educación básica: contextos que llevaron a la implementación de Parfor}

Citação: DAMASCENO, L, L; FONTES, M, G. Formação de professores para a qualidade na educação básica: contextos que conduziram à implementação do Parfor. Jornal de Políticas Educacionais. V. 13, n. 44. Dezembro de 2019.

http://10.5380/jpe.v13i0.67995

\begin{abstract}
Resumo
Este artigo apresenta uma breve contextualização da Política Nacional de Formação Docente no cenário nacional analisando o Plano Nacional de Formação de Professores da Educação Básica (Parfor). Esse Plano tem como principal objetivo adequar a formação dos professores em exercício na rede púbica de Educação Básica à disciplina que ministram em sala de aula, promovendo a articulação entre as instituições de ensino superior e as redes de ensino e, consequentemente, a melhoria no desempenho das escolas nos processos de avaliação sobre a qualidade do processo de ensino e aprendizagem na rede pública. Pretende-se resgatar as principais características do Parfor no contexto de seu lançamento e manutenção ao longo dos anos e identificar o papel da Capes no âmbito das ações voltadas para a formação de professores. Na retrospectiva analisada, constata-se
\end{abstract}

\footnotetext{
${ }^{1}$ Mestrado em Educação pela Universidade de Brasília, Brasil(2019). Assistente em Ciência e Tecnologia da Coordenação de Aperfeiçoamento de Pessoal de Nível Superior (CAPES), Brasil. E-mail: emaildalo@gmail.com. Orcid: https://orcid.org/0000-0002-0077-5709

2 Doutoranda em Educação em Ciências pela Universidade Federal do Rio Grande do Sul (UFRGS), mestre em Educação em Ciências pela mesma Universidade, graduada em Pedagogia pela Universidade de Brasília (UnB). Atualmente é analista em ciência e tecnologia da Coordenação de Aperfeiçoamento de Pessoal de Nível Superior (CAPES) E-mail: mari.gcfontes@gmail.com. Orcid: https://orcid.org/0000-0003-0863-4983
} 
que o Parfor assume um papel importante na busca pela adequação da formação docente e se consolida como uma importante ação para a formação dos profissionais do magistério da educação básica. As ações do Parfor desenvolvidas em articulação entre os diversos entes da federação, as redes de ensino e as universidades é um importante passo na busca da melhoria do ensino nas escolas públicas.

Palavras-chaves: Formação docente; Parfor; Política Nacional.

\begin{abstract}
This article presents a brief contextualization of the National Teacher Training Policy in the national scenario, analyzing the National Training Plan for Basic Education Teachers (Parfor). This Plan has as main objective to adapt the training of practicing teachers in the public network of Basic Education to the discipline they teach in classroom, promoting the articulation between higher education institutions and teaching networks and, consequently, the improvement in the performance of the schools in the processes of evaluation on the quality of the process of teaching and learning in the public network. The aim is to recover Parfor's main characteristics in the context of its creation and maintenance over the years and to identify the role of Capes in the scope of actions aimed at teacher training. In the retrospective analyzed, it is verified that Parfor assumes an important role in the search for the adequacy of teacher training and it is consolidated as an important action for the training of teachers in the basic education teaching profession. The Parfor actions developed in articulation between different entities of the federation, the educational networks and the universities are an important step in the search of the improvement of teaching in public schools.
\end{abstract}

Keywords: Teacher training; Parfor; Nacional Policy.

\title{
Resumen
}

Este artículo presenta una breve contextualización de la Política Nacional de Formación Docente en el escenario nacional que analiza el Plan Nacional de Formación de Profesores de Educación Básica en Brasil (Parfor). Este plan tiene como objetivo principal adaptar la capacitación de los docentes en ejercicio en la red pública de Educación Básica a la disciplina que imparten en el aula, promoviendo la articulación entre las instituciones de educación superior y las redes de enseñanza y, en consecuencia, la mejora del rendimento de escuelas en los procesos de evaluación de la calidad del proceso de enseñanza y aprendizaje en la red pública. El objetivo es recuperar las características principales de Parfor en el contexto de su lanzamiento y mantenimiento a lo largo de los años e identificar el papel de CAPES en el alcance de las acciones dirigidas a la formación del profesorado. En la retrospectiva analizada, se verifica que Parfor asume un papel importante en la búsqueda de la adecuación de la formación docente y se consolida como una acción importante para la formación docente de la profesión docente de educación básica. Las acciones de Parfor desarrolladas en articulación entre las diferentes entidades de la federación, las redes educativas y las universidades son un paso importante en la búsqueda de la mejora de la educación en las escuelas públicas.

Palabras clave: Formación docente; Parfor Política nacional. 


\section{INTRODUÇÃO}

No Brasil existem mais de 430 mil professores da educação básica atuando em sala de aula sem formação em nível superior (BRASIL, 2018). Esse é um dado inquietante, considerando-se a profusão de dispositivos legais existentes no país que regulam a formação de professores para a educação básica, estabelecendo os níveis (superior), os locais (Universidades e Institutos Superiores) e os prazos para que todos os professores obtenham a formação adequada.

O reconhecimento da importância da formação e da valorização do professor para a melhoria da qualidade da educação é um consenso no âmbito dos discursos acadêmicos e políticos e tem sido cada vez mais enfatizado no escopo das legislações concernentes à política educacional brasileira.

A Constituição de 1998 foi, dentre as tantas que tivemos, aquela que mais se debruçou sobre o tema educação e destacou a garantia do padrão de qualidade do ensino ministrado como princípio constitucional da educação nacional, conforme previsto no artigo 206, inciso VII, da Carta Magna. Em ato contínuo, a Lei de Diretrizes e Bases da Educação Nacional - LDB, no 9394/96 estabelece, em seu Art. 42, que "a formação de docentes para atuar na educação básica far-se-á em nível superior, em curso de licenciatura plena, admitida, como formação mínima para o exercício do magistério na educação infantil e nos cinco primeiros anos do ensino fundamental, a oferecida em nível médio, na modalidade normal".

Esses marcos legais, juntamente com os dois Planos Nacionais de Educação - um, com vigência de 2001 a 2010 e outro, com vigência de 2014 a 2024 - são os principais instrumentos de defesa do direito à educação no Brasil e, como consequência deles, se fez necessária uma expansão física das redes educacionais, bem como uma ampliação do quadro de professores para atender a essa expansão e assim, abriram caminho para uma proliferação de normas, regulamentações e criação de políticas públicas voltadas à universalização do direito à educação.

De maneira geral, na década de 90 intensificou-se o movimento de avaliação das escolas públicas com o objetivo de elaborar e implementar políticas mais objetivas e eficazes na melhoria da qualidade do ensino. As reflexões sobre a importância da formação com qualidade desde o início da vida escolar até o ensino superior tornaram-se o princípio norteador das ações no âmbito das políticas educacionais. 
Uma vez reconhecida a importância da formação docente para a garantia da qualidade do ensino, que é um preceito constitucional, concordamos com Demo (2002) na afirmação de que o professor é "o profissional dos profissionais" e que ele precisa, portanto, ser "a cara da formação primorosa". Assim, pela importância estratégica da profissão, o professor deveria passar por processo formativo dos mais exigentes e completos.

Nessa perspectiva, Neto e Maciel (2011, p.73) afirmam que "é direito do professor e dever do Estado proporcionar condições favoráveis de formação completa, apropriada e eficaz para enfrentar os grandes desafios de uma sociedade em constante e profundas transformações". Faz-se necessário, portanto, que o poder público tome iniciativas e desenvolva políticas que promovam a formação inicial e continuada de professores para garantir o princípio constitucional do padrão de qualidade do ensino ministrado nas escolas públicas brasileiras. "São iniciativas necessárias, oportunas e respondem a duas questões historicamente desafiadoras: a formação como responsabilidade individual do profissional da educação e sua dificuldade ou impossibilidade de acesso às universidades públicas" (VIEIRA, 2008, p.26).

Apesar da existência anterior de iniciativas de implementação de programas e ações do Estado voltados à formação docente, observa-se que foi há pouco mais de uma década que a formação de professores passou a ocupar um papel central para o Governo Federal, traduzindo o avanço do processo de responsabilização do poder público pelo desempenho, pela formação e pela carreira docente. Até então, as políticas docentes no país ocorriam de forma fragmentada e dispersa, sem diálogo entre os programas de formação ofertados pelas Instituições de Ensino Superior e as reais demandas das redes de educação básica.

Nesse sentido, inaugurou-se um conjunto de ações com o objetivo de promover, em regime de colaboração, a articulação entre as demandas das redes de educação básica e os programas de formação oferecidos pelas instituições de ensino superior, que, até então, ocorriam de forma fragmentada e dispersa. Essa articulação, apoiada por um grande aparato institucional montado pelo Ministério da Educação, veio delinear uma política nacional de formação docente, que se coaduna com a perspectiva de criação de um Sistema Nacional de Educação (GATTI; BARRETO; ANDRÉ, 2011).

A formação docente, diante desse contexto, ampliou seu espaço na agenda nacional, com a criação de diversos projetos e programas governamentais, com 
crescimento das pesquisas sobre o tema e, também, com a reformulação das políticas específicas voltadas para a melhoria dos índices de desempenho dos alunos e das escolas da rede pública de educação básica.

A configuração da atual política de formação docente começou a ser desenhada no ano de 2007, mais precisamente a partir da Lei 11.502/2007, que alterou a estrutura da Coordenação de Pessoal de Aperfeiçoamento de Pessoal de Nível Superior - Capes, acrescentando às suas atribuições, antes voltadas exclusivamente ao Sistema Nacional de Pós-graduação, a indução e o fomento da formação inicial e continuada de professores da educação básica nas modalidades presencial e a distância. Essa nova atribuição foi ratificada pelo Decreto 6.755/2009, que instituiu a Política Nacional de Formação de Profissionais do Magistério da Educação Básica.

A partir dessas considerações introdutórias, este artigo apresenta um breve panorama sobre a Política Nacional de Formação de Professores da Educação Básica a fim de contribuir para o debate sobre os desafios da qualidade e equidade na educação básica, discutindo a centralidade da formação de professores para o enfrentamento desses desafios tendo como unidade de análise o Plano Nacional de Formação de Professores da Educação Básica (Parfor).

\section{CONTEXTO E INSTITUCIONALIDADE QUE CONDUZIRAM À ELABORAÇÃO E IMPLEMENTAÇÃO DO PARFOR}

Os resultados dos investimentos em políticas educacionais são percebidos lentamente pela sociedade, entretanto é certo que sua a ausência traria um impacto ainda maior no desenvolvimento econômico, científico e social do país. Inevitavelmente, a qualidade das escolas de educação básica se refletirá na qualidade do ensino superior e da pós-graduação.

Nessa perspectiva, surge desde a instauração da República Federativa do Brasil a necessidade de elaboração de um plano para a educação em todo o território nacional, principalmente atrelada à ideia de desenvolvimento do país.

O primeiro Plano Nacional de Educação surgiu em 1962, elaborado já na vigência da primeira Lei de Diretrizes e Bases da Educação Nacional, Lei no 4.024, de 1961. Ele não foi proposto na forma de um projeto de lei, mas apenas como uma iniciativa do Ministério da Educação e Cultura, iniciativa essa aprovada pelo então Conselho Federal de Educação. Era basicamente um conjunto de metas 
DAMASCENO, L, L; FONTES, M, G. Formação de professores para a qualidade na educação básica: contextos que conduziram à implementação do Parfor

quantitativas e qualitativas a serem alcançadas num prazo de oito anos. (PNE 2001-2010, p. 5).

No Brasil, o reconhecimento da importância da formação básica se torna mais evidente com a Constituição de 1988, que estabeleceu a educação como um direito social. De acordo com o art. 6º dessa Carta Magna, "são direitos sociais a educação, a saúde, a alimentação, o trabalho, a moradia, o lazer, a segurança, a previdência social, a proteção à maternidade e à infância, a assistência aos desamparados, na forma desta Constituição" (Redação dada pela Emenda Constitucional no 90, de 2015).

Foi somente com a Constituição de 1988, marco inicial de um Estado de bemestar social no país, e com o fortalecimento da democracia, que grandes transformações começaram a ocorrer. A Educação se tornou, finalmente, um direito dos cidadãos brasileiros. (ABRUCIO, 2016, p.10).

Para atender as determinações da Constituição, desencadeou-se no Brasil um processo de expansão do acesso à educação básica que culminou na elevação da taxa de matrícula nesse nível de ensino, trazendo à tona diversas questões, entre as quais a preocupação com a oferta de um ensino de qualidade. Ao conjunto de preocupações relacionadas com as mudanças no cenário da sociedade brasileira, destaca-se também a equidade.

O aumento da qualidade e da equidade no campo educacional depende de várias ações. Um dos pontos nevrálgicos tem a ver com o capital humano e se traduz na criação de uma sólida carreira de magistério, com professores bem formados e profissionalizados. Para atingir esse objetivo, uma das peças centrais é a formação e o aperfeiçoamento dos docentes, seja dos que vão entrar na carreira, seja dos que nela estão. (ABRUCIO, 2016, p. 11).

Portanto, se depreende também, que qualidade e equidade em educação estão intrinsecamente relacionadas à formação de professores e sua importância encontra-se evidencia na literatura e nos documentos das políticas educacionais.

No Brasil, políticas educacionais implantadas desde meados da década de 1990 passaram a destinar grande parte dos recursos disponíveis à formação e ao desenvolvimento dos professores, como foi o caso do Fundo de Manutenção e Desenvolvimento do Ensino Fundamental e de Valorização do Magistério (Fundef), instituído pela Emenda Constitucional n. 14, de 12 de setembro de 1996, criado por iniciativa do Governo Federal. (BAUER, 2011, p. 2).

Para Valliant, Darling-Harmond e Fernandes (apud BAUER, CASSETTARI, OLIVEIRA, 2017, p. 944), as

Reformas educacionais impulsionadas em quase todos os países da América Latina nos anos 1990 tiveram como foco modificações na gestão dos sistemas (descentralização administrativa) e no currículo (estabelecimento de parâmetros e diretrizes comuns), sem colocar as políticas docentes em posição 
DAMASCENO, L, L; FONTES, M, G. Formação de professores para a qualidade na educação básica: contextos que conduziram à implementação do Parfor

de destaque. Tal tendência se modifica com a constatação da insuficiência dessas reformas.

Um passo importante na organização da educação e no direcionamento de políticas públicas foi a publicação da Lei de Diretrizes e Bases da Educação, Lei 9.394/1996, que estabeleceu diretrizes para a educação nacional retomando a ideia do plano para a educação iniciado na década de 60. Conforme artigo 9o destacou-se a importância da elaboração de um Plano Nacional de Educação pela União em articulação com os estados, o Distrito Federal e os municípios.

Em 2001, este Plano Nacional de Educação (PNE) foi aprovado por meio da Lei $\mathrm{n}^{\mathrm{o}}$ 10.172/2001, prevendo a articulação entre os estados, o Distrito Federal e os municípios para a elaboração de planos decenais, prevendo o acompanhamento e a avaliação das ações. Além disso, determinou-se a União como a responsável por instituir o Sistema Nacional de Avaliação e por criar mecanismos de acompanhamento das metas do PNE.

Apresentando diagnósticos, diretrizes, objetivos e metas para cada etapa de ensino da educação básica, para o ensino superior e para cada modalidade de ensino, o PNE referente ao decênio 2001-2010 destacou separadamente a situação do magistério da educação básica incluindo na pauta das políticas públicas direcionadas à melhoria da educação básica a formação dos professores e a valorização do magistério.

\footnotetext{
A melhoria da qualidade do ensino, que é um dos objetivos centrais do Plano Nacional de Educação, somente poderá ser alcançada se for promovida, ao mesmo tampo, a valorização do magistério. Sem esta, ficam baldados quaisquer esforços para alcançar as metas estabelecidas em cada um dos níveis e modalidades do ensino. Essa valorização só pode ser obtida por meio de uma política global de magistério, a qual implica, simultaneamente, a formação profissional inicial; as condições de trabalho, salário e carreira; a formação continuada. (PNE 20012010, p.61).
}

Com objetivo de implementar o regime de colaboração entre os entes federados e de incentivar iniciativas mais direcionadas para a melhoria dos resultados do ensino no país, a emenda constitucional no 59/2009 alterou a redação do artigo 214 da Constituição Federal que passou a definir o PNE como um norteador para as ações voltadas para a educação básica prevendo o direcionamento de recursos para a melhoria da qualidade da educação básica em todo o país.

Art. 214. A lei estabelecerá o plano nacional de educação, de duração decenal, com o objetivo de articular o sistema nacional de educação em regime de colaboração e definir diretrizes, objetivos, metas e estratégias de implementação para assegurar a manutenção e desenvolvimento do ensino em seus diversos 
níveis, etapas e modalidades por meio de ações integradas dos poderes públicos das diferentes esferas federativas que conduzam a:

I - erradicação do analfabetismo;

II - universalização do atendimento escolar;

III - melhoria da qualidade do ensino;

IV - formação para o trabalho;

V - promoção humanística, científica e tecnológica do País.

VI - estabelecimento de meta de aplicação de recursos públicos em educação como proporção do produto interno bruto." (BRASIL, 1988)

Em 2007, o censo escolar adotou um novo modelo de formulário e a coleta de dados da educação básica foi marcada pela utilização do sistema Educacenso pelo Instituto Nacional de Estudos e Pesquisas Educacionais Anísio Teixeira - Inep, ampliando o olhar sobre a situação das escolas da rede pública de educação básica e, principalmente, sobre a formação de seus professores.

O estudo exploratório sobre o professor brasileiro realizado pelo Inep com base nos dados do censo escolar de 2007 indicaram a importância de informações sobre a adequação do perfil dos professores à disciplina que lecionam na escola para o desenvolvimento de políticas de formação docente adequadas à realidade e à necessidade das redes de ensino.

Para os anos finais do ensino fundamental, o censo escolar de 2007 apresentou a quantidade de professores atuando por disciplina, conforme tabela 1, observando que o mesmo professor pode possuir mais de uma formação e lecionar mais de uma disciplina.

Tabela 1. Número de professores dos anos finais do Ensino Fundamental por disciplina que lecionam de acordo com o censo de 2007

Professores por disciplina

\section{Disciplina}

\section{Química}

Física

Matemática

Biologia

Ciências

Língua/Literatura Portuguesa

Língua/Literatura

inglês

\begin{tabular}{lllll}
\hline $\begin{array}{l}\text { Língua/Literatura } \\
\text { Espanhol }\end{array}$ & estrangeira: & 6.721 & 6.120 & 601 \\
\hline $\begin{array}{l}\text { Língua/Literatura } \\
\text { Outra }\end{array}$ & estrangeira: & 1.364 & 1.268 & 96 \\
\hline Artes/Educação Artística & 90.454 & 83.177 & 7.277 \\
\hline Educação Física & 74.848 & 69.593 & 5.255 \\
\hline História & 113.239 & 105.613 & 7.626 \\
\hline Geografia & 110.269 & 102.626 & 7.643
\end{tabular}

Com Sem
licenciatura licenciatura

$2.385 \quad 284$

$2.412 \quad 299$

$134.461 \quad 10.836$

$1.705 \quad 169$

$112.060 \quad 9.035$

$148.420 \quad 10.117$

$76.002 \quad 4.978$

158.537

80.980


DAMASCENO, L, L; FONTES, M, G. Formação de professores para a qualidade na educação básica: contextos que conduziram à implementação do Parfor

\begin{tabular}{llll} 
Filosofia & 5.138 & 4.700 & 438 \\
\hline Estudos Sociais/Sociologia & 1.702 & 1.527 & 175
\end{tabular}

(Fonte: MEC/Inep/Deed, p. 38)

A análise não só do quantitativo de professores atuando em cada disciplina, mas também da compatibilidade entre a formação do professor e a disciplina que ministra na escola foi uma grande conquista para a elaboração das políticas voltadas para a formação dos profissionais do magistério.

Considerando a adequação da formação docente à disciplina que ministram em sala de aula, a distribuição dos docentes nos anos finais do ensino fundamental por área de formação de nível superior no censo escolar de 2007 ficou distribuída conforme gráfico 1:

\section{Gráfico 1. Adequação da formação dos professores que atuam nos anos finais do ensino fundamental de acordo com o censo 2007}

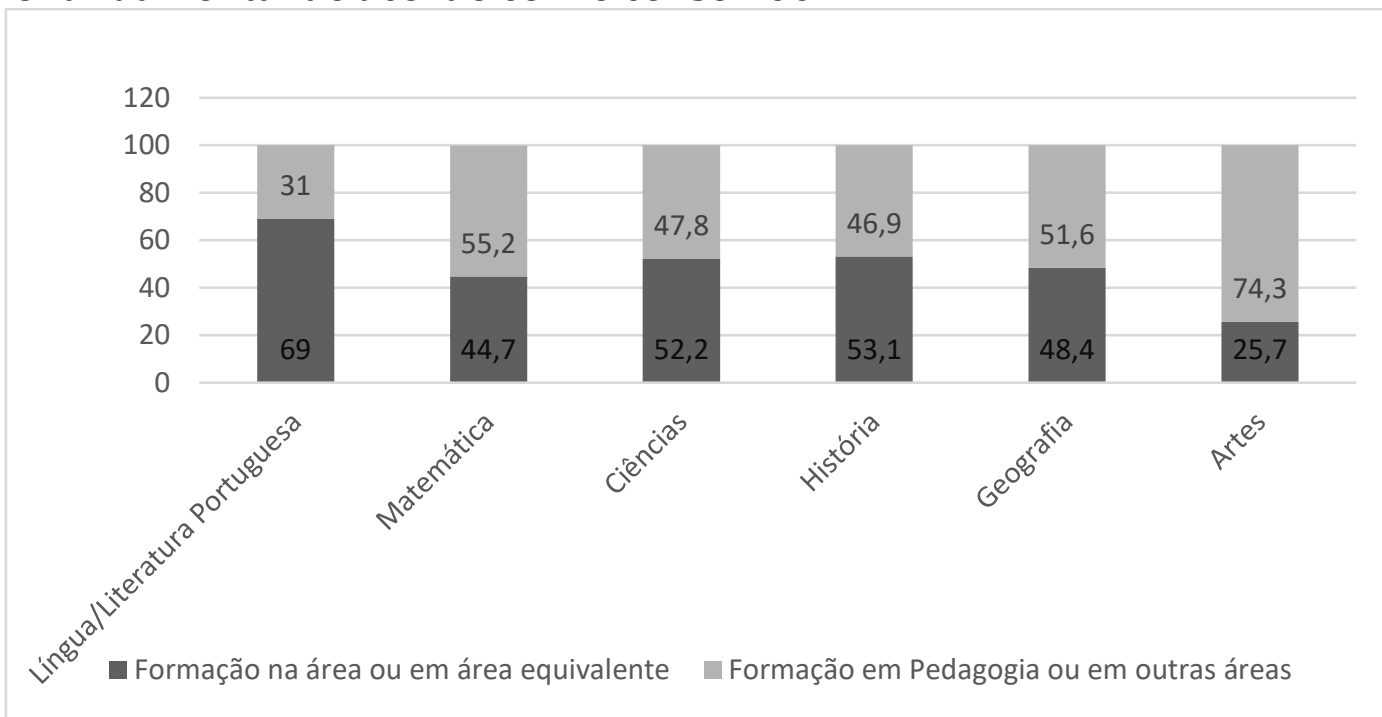

(Fonte: MEC/Inep/Deed, p.39)

A análise dos dados apresentados na tabela 1 relacionada aos percentuais de adequação de formação apresentados no gráfico 1 indicam, por exemplo, que em relação à disciplina de matemática, do total de 145.297 professores, $44,7 \%$ possuem formação em matemática ou em área equivalente. Neste universo, 55,2\% ministram o conteúdo de matemática sem formação adequada, correspondendo a aproximadamente 80.203 professores. Já em relação à disciplina de ciências, do total de 121.095 professores 47,8\% atuam sem formação adequada, correspondendo a aproximadamente 57.883 professores.

Além dessas informações, no censo escolar de 2007 encontrou-se a predominância de composição de turmas com 35 alunos. Ao fazer ainda a relação entre os dados, obtém- 
se que, em matemática, em torno de 2,8 milhões de estudantes dos anos finais do ensino fundamental em algum momento de sua jornada escolar foram apresentados à linguagem matemática por um profissional sem a formação na área. Já em ciências, aproximadamente 2 milhões de estudantes tiveram contato com conteúdos de ciências acompanhados por profissionais do magistério sem a formação adequada para o ensino de ciências.

O mesmo estudo foi apresentado para o ensino médio, onde identificou-se o número de professores de ensino médio e sua distribuição por disciplina conforme a tabela 2. Para o ensino médio, também foi considerado que o mesmo professor pode possuir mais de uma formação e lecionar mais de uma disciplina.

Tabela 2 - Número de professores do Ensino Médio por disciplina que lecionam de acordo com o censo de 2007

\begin{tabular}{|c|c|c|c|}
\hline \multirow[b]{2}{*}{ Disciplina } & \multicolumn{3}{|c|}{ Professores por disciplina } \\
\hline & Total & $\begin{array}{c}\text { Com } \\
\text { licenciatura }\end{array}$ & $\begin{array}{c}\text { Sem } \\
\text { licenciatura }\end{array}$ \\
\hline Química & 38.871 & 35.183 & 3.688 \\
\hline Física & 44.566 & 40.804 & 3.762 \\
\hline Matemática & 67.447 & 62.866 & 4.581 \\
\hline Biologia & 43.480 & 40.560 & 2.920 \\
\hline Ciências & 193 & 184 & 9 \\
\hline Língua/Literatura Portuguesa & 78.628 & 74.919 & 3.709 \\
\hline $\begin{array}{l}\text { Língua/Literatura estrangeira: } \\
\text { inglês }\end{array}$ & 45.014 & 42.433 & 2.581 \\
\hline $\begin{array}{l}\text { Língua/Literatura } \\
\text { Espanhol }\end{array}$ & 5.998 & 5.449 & 549 \\
\hline $\begin{array}{l}\text { Língua/Literatura estrangeira: } \\
\text { Outra }\end{array}$ & 735 & 700 & 35 \\
\hline Artes/Educação Artística & 33.417 & 31.123 & 2.294 \\
\hline Educação Física & 33.582 & 31.619 & 1.963 \\
\hline História & 48.893 & 46.609 & 2.284 \\
\hline Geografia & 45.536 & 43.275 & 2.261 \\
\hline Filosofia & 27.085 & 25.175 & 1.910 \\
\hline Estudos Sociais/Sociologia & 19.776 & 18.408 & 1.368 \\
\hline
\end{tabular}

Considerando a adequação da formação docente à disciplina que ministram em sala de aula, a distribuição dos docentes do nível médio por área de formação ficou distribuída conforme gráfico 2: 


\section{Gráfico 2 - Adequação da formação de professores que atuam no ensino médio de acordo com o censo 2007}

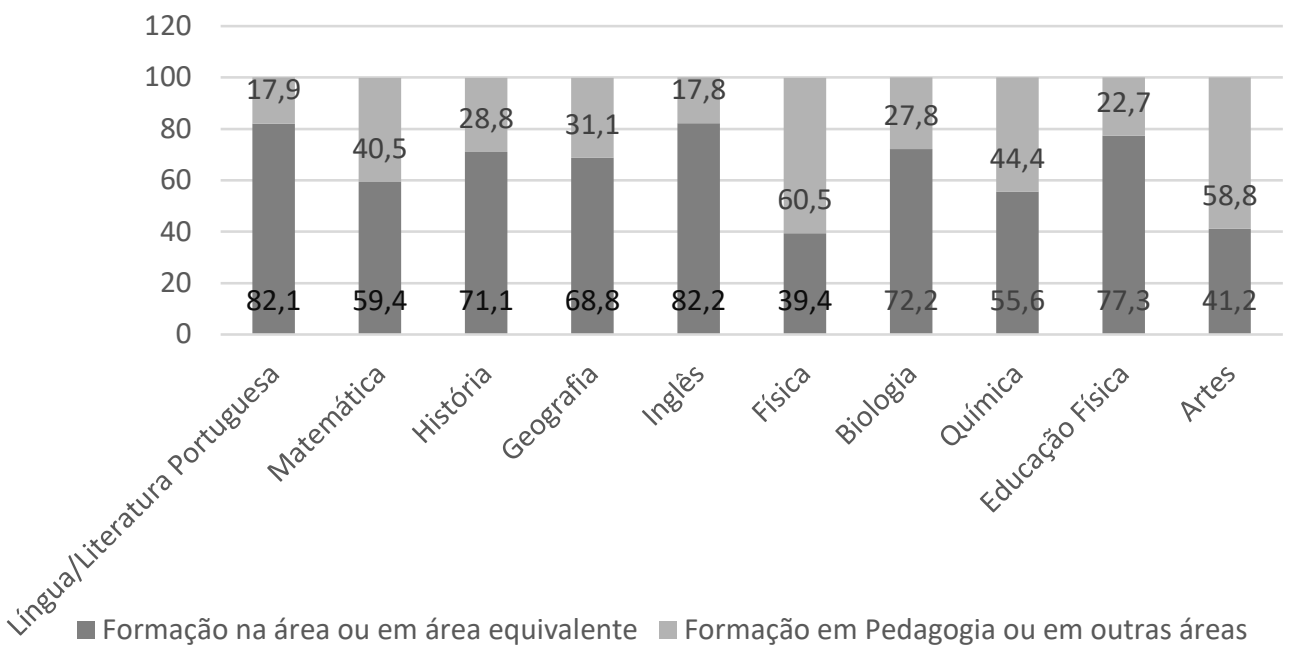

(Fonte: MEC/Inep/Deed, p 39)

A análise da adequação da formação docente nas disciplinas de matemática, física, biologia e química indicam que, para matemática, do total de 67.447 professores, $40,5 \%$ atuam sem formação adequada, para física, do total de 44.566 professores, $60,5 \%$ atuam se formação, para biologia, do total de 43.480 professores $27,8 \%$ não possuem formação na área e, por fim, em química, do total de 38.871 professores, 44,4\% atuam sem a formação na área.

Os dados divulgados pelo Inep indicaram a necessidade de se repensar as políticas públicas para a formação de professores e destacaram a importância do lançamento de ações voltadas não só para a formação dos professores em nível superior, mas também para a adequação da formação dos profissionais do magistério em relação à sua atuação em sala de aula. Nesse contexto, inicia-se o desenho de uma política com novas características, objetivando não só a formação dos docentes em nível superior, mas a qualificação das ações e programas considerando também a adequação da formação docente.

A implementação de uma política voltada tanto para a formação dos docentes quanto para a sua adequação em relação aos conteúdos ministrados em sala de aula é de fundamental importância para o desenvolvimento de um ensino de qualidade nas escolas. 
Conforme destacam TREVISAN, TREVISAN e RIBEIRO (2018) “o desenvolvimento profissional docente inclui múltiplas contribuições e se constitui por um processo contínuo de aprendizagem, que afeta diretamente as práticas pedagógicas desenvolvidas". (p.354)

Ainda de acordo com esses autores, o processo de profissionalização dos professores é muito importante e desencadeia uma relação entre os conhecimentos obtidos na formação e os saberes que são ressignificados no exercício da profissão. Daí a importância das ações que centralizaram o foco das políticas na formação dos profissionais do magistério.

Dentre essas ações, pode-se destacar o Plano de metas Compromisso todos pela Educação, lançado pelo governo federal em 2007 por meio do Decreto 6.094/2007, definido como uma "conjugação dos esforços da União, Estados, Distrito Federal e Municípios, atuando em regime de colaboração, das famílias e da comunidade, em proveito da melhoria da qualidade da educação básica". A adesão ao Plano ocorreu em caráter voluntário e para cumprir as metas do Compromisso os entes foram apoiados pelo Ministério da Educação para a elaboração do conjunto articulado de ações, denominado PAR.

A formação dos professores em exercício na rede pública de educação básica foi uma das prioridades do PAR e o Ministério da Educação passou a adotar medidas para dinamizar a concretização do planejamento estratégico de cada ente. "As ações do planejamento estratégico tiveram como embasamento inicial o envio pelo Ministério da Educação aos estados do Ofício Circular GM/MEC no 118/08, em julho de 2008, propondo a adoção de uma estratégia para "estimular arranjos educacionais no âmbito do estado, coordenados pela Secretaria de Estado de Educação, envolvendo também as administrações municipais e as instituições públicas que oferecem cursos de licenciatura". (BRASIL, MEC, Plano Nacional de Formação de Professores da Educação Básica, p.6)

Nesse contexto, o Ministério da Educação instituiu a Política Nacional de Formação de Profissionais do Magistério com a publicação do Decreto 6.755, de 29 de janeiro de 2009, com o objetivo principal de "organizar, em regime de colaboração entre a União, os Estados, o Distrito Federal e os Municípios, a formação inicial e continuada dos profissionais do magistério para as redes públicas da educação básica.” (BRASIL, 2009). 
Por meio da política lançada pelo Decreto 6.755/2009, a articulação entre os entes da federação foi organizada e implementada por meio da criação dos Fóruns Estaduais Permanentes de Apoio à Formação Docente, que cumpriram um papel fundamental na implementação da política nacional, principalmente em relação às ações voltadas para a formação dos profissionais do magistério.

Além disso, a Política disciplinou a atuação da Coordenação de Aperfeiçoamento de Pessoal de Nível Superior (Capes) no que se refere às ações voltadas para a formação inicial e continuada de professores da educação básica. As principais ações desenvolvidas pela Capes neste novo cenário de atuação incluíram a valorização e o apoio à iniciação à docência e à oferta emergencial de cursos de formação para os docentes das redes públicas de educação básica.

A política nacional de formação docente induzida pelo Ministério da Educação “traduz o avanço do processo de responsabilização do poder público pelo desempenho e pela carreira dos professores da educação básica e considera a formação como um processo contínuo de construção de uma prática docente qualificada e de afirmação da identidade, da profissionalidade e da profissionalização dos professores". (GATTI, BARRETO, ANDRÉ, 2011, p.49)

0 resultado de todas as ações para estabelecer um compromisso articulado entre os entes da federação, envolvendo diversos atores, com o principal objetivo de fortalecer e qualificar o ensino nas escolas públicas de educação básica culminou no lançamento do Plano Nacional de Formação de Professores da Educação Básica (Parfor), destinado aos professores em exercício com o objetivo principal de adequar a formação dos docentes às disciplinas que ministram em sala de aula.

O Parfor foi desenvolvido na modalidade presencial e ficou sob a responsabilidade da Diretoria de Educação Básica da Capes com objetivo de induzir e fomentar a oferta de cursos de formação superior para docentes ou tradutores intérpretes de libras em exercício na rede pública de educação básica, para que estes profissionais adequem sua formação conforme as exigências da Lei de Diretrizes e Bases da Educação Nacional e contribuam para a melhoria da qualidade da educação básica no País.

O Plano se consolidou com a indução da oferta de cursos de Licenciatura, para profissionais do magistério sem formação superior, cursos de segunda licenciatura, para profissionais do magistério que atuam em área distinta da sua formação inicial, e cursos 
de formação pedagógica para profissionais do magistério com formação superior, mas sem a formação em licenciatura.

Reforçando as ações até então desenvolvidas pelo Ministério da Educação, em 2014 foi aprovado o Plano Nacional de Educação (PNE) para o decênio 2014-2024, por meio da lei no 13.005/2014, apresentando as seguintes diretrizes: erradicar o analfabetismo, universalizar o atendimento escolar, superar as desigualdades educacionais, promover melhorias da qualidade da educação, induzir a formação para o trabalho e para a cidadania, promover o princípio da gestão democrática da educação pública, incentivar a promoção humanística, científica, cultural e tecnológica do País, estabelecer meta de aplicação de recursos públicos em educação como proporção do Produto Interno Bruto - PIB, que assegure atendimento às necessidades de expansão, com padrão de qualidade e equidade, valorizar os profissionais da educação e promover os princípios do respeito aos direitos humanos, à diversidade e à sustentabilidade socioambiental.

O Parfor continuou tendo grande importância no cenário das políticas públicas da educação brasileira, sendo suas ações desenvolvidas em consonância com a meta 15 do PNE 2014-2024, estabelecida para "garantir, em regime de colaboração entre a União, os Estados, o Distrito Federal e os Municípios, no prazo de 1 (um) ano de vigência deste PNE, política nacional de formação dos profissionais da educação de que tratam os incisos I, II e III do caput do art. 61 da Lei no 9.394, de 20 de dezembro de 1996, assegurado que todos os professores e as professoras da educação básica possuam formação específica de nível superior, obtida em curso de licenciatura na área de conhecimento em que atuam".

Para monitoramento da Meta 15 do PNE 2014-2024, o Inep lançou o Indicador de adequação da formação do docente na educação básica, descrito como a "classificação dos docentes segundo a adequação de sua formação inicial à disciplina e etapa de atuação na educação básica, com vistas à construção de indicador que avalie o cumprimento das orientações legais". (BRASIL, Inep, 2014)

O cruzamento de informações levantadas no censo escolar de 2013 para aferição do indicador de adequação de formação do docente na educação básica gerou a definição de 5 perfis de regência das disciplinas pelo Inep conforme apresentado na tabela 3: 
DAMASCENO, L, L; FONTES, M, G. Formação de professores para a qualidade na educação básica: contextos que conduziram à implementação do Parfor

Tabela 3. Categorias de adequação da formação do docente em relação à disciplina que leciona

\begin{tabular}{ll} 
Grupo & \multicolumn{1}{c}{ Descrição } \\
\hline $\mathbf{1}$ & $\begin{array}{l}\text { Docentes com formação superior de licenciatura na mesma disciplina que } \\
\text { lecionam ou bacharelado na mesma disciplina com curso de complementação } \\
\text { pedagógica concluído. }\end{array}$ \\
\hline $\mathbf{2}$ & $\begin{array}{l}\text { Docentes com formação superior de bacharelado na disciplina } \\
\text { correspondente, mas sem licenciatura ou complementação pedagógica. }\end{array}$ \\
\hline $\mathbf{3}$ & $\begin{array}{l}\text { Docentes com licenciatura em área diferente daquela que leciona ou com } \\
\text { bacharelado nas disciplinas da base curricular comum e complementação } \\
\text { pedagógica concluída em área diferente daquela que leciona. }\end{array}$ \\
\hline $\mathbf{4}$ & $\begin{array}{l}\text { Docentes com outra formação superior não considerada nas categorias } \\
\text { anteriores. }\end{array}$ \\
\hline $\mathbf{5}$ & Docentes que não possuem curso superior concluído. \\
\hline
\end{tabular}

(Fonte: Nota Técnica Inep 020/2014).

As ações do Parfor consolidaram-se para adequar a formação dos professores por meio do acesso dos docentes à formação requerida na LDB por intermédio da oferta de turmas especiais em cursos de licenciatura, para os professores classificados na categoria 5, segunda licenciatura, para professores classificados nas categorias 3 e 4, e cursos de formação pedagógica para docentes classificados na categoria 2.

As turmas formadas no âmbito do Parfor, denominadas turmas especiais, são implementadas em licenciaturas já ofertadas pelas instituições de ensino superior e são compostas exclusivamente pelos profissionais do magistério que se inscreveram no sistema Plataforma Freire e tiveram sua participação no programa validada pela Secretaria de Educação.

O Parfor também tem se consolidado como uma ação para promover o regime de colaboração, por meio dos Fóruns Estaduais Permanentes de Apoio à Formação Docente. Estas entidades têm se constituído em eficientes espaços de debate e protagonismo na busca pela manutenção das ações para a formação inicial dos profissionais do magistério em exercício, bem como de análise e acompanhamento do Parfor.

\section{CONSIDERAÇÕES FINAIS}

O Parfor, lançado em 2009, já alcançou um total de 94.247 matrículas. Desse total, 33.801 docentes concluíram o curso de licenciatura ou formação pedagógica e ainda há 37.809 com matricula ativa no programa. A taxa de evasão registrada permanece em torno de $22,83 \%$. 
Em 2016, o Decreto 6.755/2009 foi revogado e o Decreto 8.752/2016 traduziu uma nova perspectiva para o cenário da Política Nacional de Formação dos Profissionais da Educação Básica. De maneira geral, a Política Nacional não sofreu grandes alterações, entretanto as atribuições da Capes foram diferenciadas das definições anteriores, sendo indicado no artigo 16 que "A Coordenação Nacional de Aperfeiçoamento de Pessoal de Nível Superior - Capes fomentará a pesquisa aplicada nas licenciaturas e nos programas de pós-graduação, destinada à investigação dos processos de ensino-aprendizagem e ao desenvolvimento da didática específica".

Mesmo neste contexto, a Capes publicou a portaria no 82/2017, definindo o Plano Nacional de Formação de Professores da Educação Básica como um Programa, mantendo suas características iniciais e conduzindo algumas alterações para alcançar melhorias no atendimento à demanda de formação apresentada pelas redes de ensino.

Como destaca o artigo $1^{0}$ da Portaria no 82/2017, “O Programa Nacional de Formação de Professores da Educação Básica - Parfor é uma ação da Coordenação de Aperfeiçoamento de Pessoal de Nível Superior - Capes, (...), em consonância com as metas 15 e 16 do Plano Nacional de Educação - PNE, Lei no 13.005, de 25 de junho de 2014 e com a Lei de Diretrizes e Bases da Educação Nacional, nº 9.394 de 20 de dezembro de 1996 e suas modificações posteriores".

Dessa maneira, foi estabelecida a continuidade das ações da Capes para a formação inicial de professores em exercício na rede pública de educação básica que culminou em 2018 com o lançamento de um novo edital para oferta de turmas especiais no âmbito do Programa, o qual teve como principais objetivos: oferecer aos professores em serviço na rede pública oportunidade de acesso à formação em nível superior em curso de licenciatura na área de conhecimento em que atuam, incentivar o desenvolvimento de propostas formativas inovadoras considerando as especificidades da formação em serviço para professores da educação básica e estimular o aprimoramento dos Projetos Pedagógicos de Curso (PPC) das licenciaturas, tendo por base as experiências observadas nas turmas especiais implementadas. (CAPES, 2018, p. 1)

Considerando o breve histórico apresentado neste artigo e a Política Nacional de Formação de Professores vigente, foi possível identificar a relevância da experiência do Parfor na construção de um ensino público de qualidade a partir da perspectiva da formação do professor aliando a sua adequação à atuação em sala de aula. Apesar das fragilidades no novo cenário político e econômico e as alterações quanto ao papel da 
Capes neste contexto, o programa ainda apresenta um grande potencial para desenvolver ações que conduzam à centralidade da formação de professores para a equidade e a qualidade na educação básica.

\section{REFERÊNCIAS}

ABRUCIO, F. L A. Formação de Professores no Brasil: Diagnóstico, agenda de políticas e estratégias para a mudança. São Paulo, Moderna, 2016.

BAUER, A. Avaliação de impacto de formação docente em serviço: o programa Letra e Vida. São Paulo, 2011.

BAUER, A. CASSETTARI, N. OLIVEIRA, R.P. Políticas docentes e qualidade da educação: uma revisão da literatura e indicações de política. Ensaio: Aval. Pol. Publ. Rio de Janeiro, v.25, n.97, p. 943-970. Out/dez 2017.

BRASIL. Constituição da República Federativa do Brasil (1988). Promulgada em 05 de outubro de 1988. Disponível em: < https://www.planalto.gov.br/ccivil_03/Constituicao/Constituicao.htm> Acesso em 24 jun. 2018.

BRASIL. Decreto no 6.755, de 29 de janeiro de 2009. Disponível em http://www.capes.gov.br/images/stories/download/legislacao/Decreto-6755-2009.pdf Acesso em 24 jun. 2018.

BRASIL. Decreto no 8.752, de 09 de maio de 2016. Disponível em http://www. planalto.gov.br/ccivil_03/_Ato2015-2018/2016/Decreto/D8752.htm\#art19 Acesso em 24 jun. 2018.

BRASIL. Ministério da Educação. Planejando a Próxima Década Conhecendo as 20 Metas do Plano Nacional de Educação. Disponível em <http://pne.mec.gov.br/images/pdf /pne_conhecendo_20_metas.pdf> Acesso em 24 jun. 2018.

BRASIL. Ministério da Educação. Plano Nacional de Formação de Professores da Educação Básica. Disponível em < http://portal.mec.gov.br/dmdocuments/livro.pdf> Acesso em 24 jun. 2018.

BRASIL. Lei no 9.394, de 20 de dezembro de 1996. Estabelece as diretrizes e bases da educação nacional. Disponível em http://www.planalto.gov.br/ccivil_03/ leis/L9394.htm> Acesso em 29 abr. 2018.

BRASIL. Lei no 10.172, de 9 de janeiro de 2001. Aprova o Plano Nacional de Educação e dá outras providências. Disponível em <http://www.planalto.gov.br/ccivil_ 03/LEIS/LEIS_2001/L10172.htm> Acesso em 24 jun. 2018.

BRASIL. Lei № 13.005, de 25 de junho de 2014. Aprova o Plano Nacional de Educação - PNE e dá outras providências. Disponível em <http://www.planalto.gov.br/CCIVIL_03/_Ato2011-2014/2014/Lei/L13005.htm> Acesso em 30 abr. 2018. 
BRASIL. MEC/Inep/Deed. Estudo exploratório sobre o professor brasileiro com base nos resultados do Censo Escolar da Educação Básica 2007. Instituto Nacional de Estudos e Pesquisas Educacionais Anísio Teixeira. - Brasília: Inep, 2009. 63 p.

Ministério da Educação. Instituto Nacional de Estudos e Pesquisas

Educacionais Anísio Teixeira - INEP. Educacenso, 2018

BRASIL. Inep. Nota Técnica 020/2014. Indicador de adequação da formação do docente da educação básica. Disponível em http://download.inep.gov.br/educacao _basicaprova_brasil_saeb/resultados/2013/nota_tecnica_indicador_de_adequacao_da_fo rmacao_do_docente_da_educacao_basica.pdf 2014

CAPES. Edital no 19/2018. Disponível em http://www.capes.gov.br/images/stories /download/editais/25052018-Edital-19-2018-SITE.pdf

CAPES. Portaria no 82, de 17 de abril de 2017. Disponível em http://www.capes.gov.br/images/stories/download/legislacao/24082017-PORTARIA82-2017-REGULAMENTO-PARFOR.pdf

CAPES. Manual Operativo do Parfor. Disponível em http://www.capes.gov.br/images /stories/download/legislacao/2782014-MANUAL-OPERATIVO-PARFOR.pdf

DEMO, P. Professor e seu direito de estudar. In: SHIGUNOV NETO, Alexandre \& MACIEL, Lizete Shizue Bomura (Orgs.). Reflexões sobre a formação de professores. Campinas: Papirus, 2002.

GATTI, B. BARRETO, E. ANDRÉ, M. Políticas docentes no Brasil: um estado da arte. Brasília, UNESCO, 2011.

NETO, A. S.; MACIEL, L. S. B. As políticas neoliberais e a formação de professores: propostas de formações simplistas e aligeiradas em épocas de transformações. In: MACIEL, L.; NETO, A. Formação de Professores. Passado, presente e futuro. 2. ed. São Paulo: Cortez Editora, 2011. p. 35-76

TREVISAN, A.C.R, TREVISAN, E.P, RIBEIRO, K. D. F. A relação entre teoria e prática no processo de desenvolvimento profissional docente: o caso da escola Luiza Nunes Bezerra. Revista Prática Docente. v. 3, n. 1, p. 352-365, jan/jun 2018.

VIEIRA, J. D. Verbos intransitivos para uma política pública. Formar, valorizar, profissionalizar. Retratos da Escola, v. 2, n. 2/3, jan./dez., 2008. 

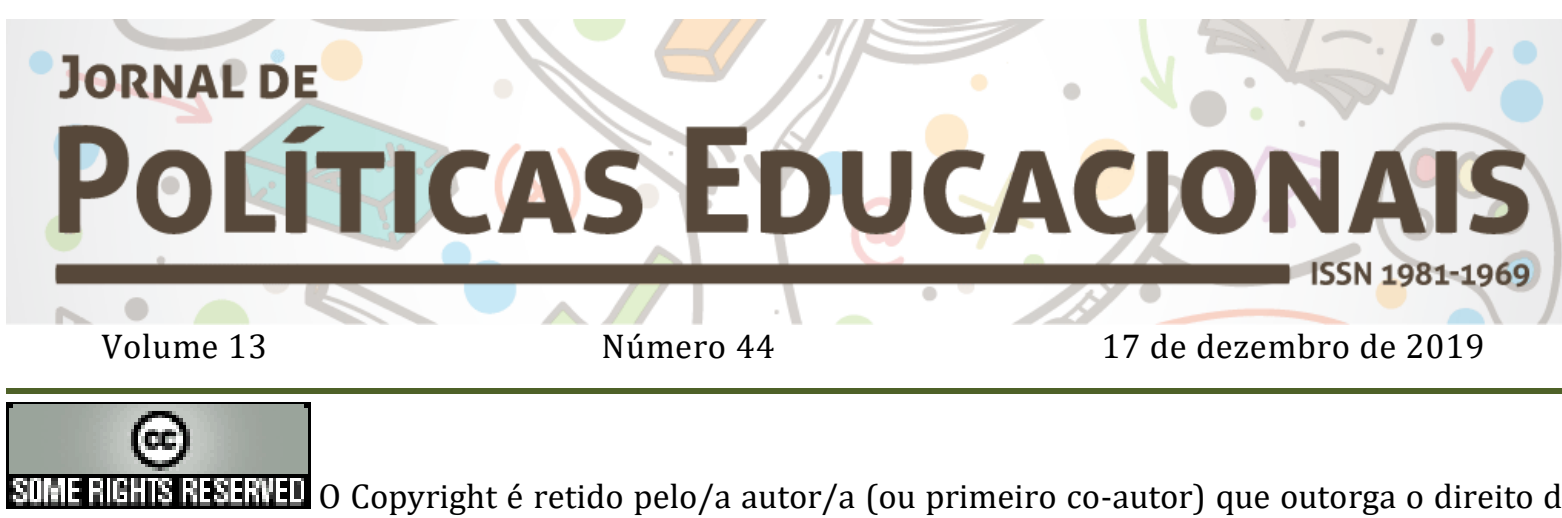
primeira publicação ao Jornal de Políticas Educacionais. Mais informação da licença de CreativeCommons encontram-se em http://creativecommons.org/licenses/by-nc-nd/2.5. Qualquer outro uso deve ser aprovado em conjunto pelo/s autor/es e pelo periódico.

JoRnal DE Políticas EdUCACIONAIS é uma publicação do Núcleo de PolíticasEducacionaisdo Setor de Educação da Universidade Federal do Paraná - NuPE/UFPR, em consórcio com a Linha de Pesquisa em Políticas Educacionais do Programa de Pós-Graduação em Educação - PPGE/UFPR, que aceita colaboração, reservando-se o direito de publicar ou não o material espontaneamente enviado à redação. As colaborações devem ser enviadas ao NuPE/UFPR, conforme orientações contidas nas páginas do periódico na internet: http://revistas.ufpr.br/ipe.

\author{
Indexação: \\ BBE - Biblioteca Brasileira de Educação (MEC/INEP) \\ Clase (Base de Datos Bibliográfica de Revistas de Ciencias Sociales y Humanidades) \\ Diadorim - Diretório de Política de Acesso Aberto das Revistas Científicas Brasileiras (IBICT) \\ Google Scholar \\ Index Copernicus \\ Portal de Periódicos (CAPES) \\ SER - Sistema Eletrônico de Revistas da Universidade Federal do Paraná (SER/UFPR) \\ Sumários de Revistas Brasileiras (FUNPEC-RP) \\ DRJI - Directory of Research Journals Indexing
}

(Periódico integralmente disponível apenas em via eletrônica)

Jornal de Políticas Educacionais / Núcleo de Políticas Educacionais da Universidade Federal do Paraná NuPE/UFPR - v.1, n. 1 (1ํㅗ semestre de 2007) - Curitiba: NuPE/UFPR.

Volume 13, número 44 - Dezembro de 2019

ISSN 1981-1969

1. Educação - Periódicos. 2. Política Educacional - Periódicos. I. NuPE/UFPR

Comitê Editorial:

Elisângela Scaff (UFPR)

Daniela de Oliveira Pires (UFPR)

Conselho Editorial:

Andréa Barbosa Gouveia (UFPR - Brasil), Cesar Tello (Universidad Nacional Tres Febrero, Argentina), Fernanda Saforcada (Universidad de Buenos Aires - UBA - Argentina), Gladys Beatriz Barreyro (USP Brasil), Gustavo Enrique Fischman, (Arizona State University - USA), Jefferson Mainardes (UEPG - Brasil), João Ferreira de Oliveira (UFG - Brasil), Juca Gil (UFRGS - Brasil), Luiz Souza Júnior (UFPB - Brasil), Ney 
DAMASCENO, L, L; FONTES, M, G. Formação de professores para a qualidade na educação básica: contextos que conduziram à implementação do Parfor

Cristina Monteiro de Oliveira (UFPA - Brasil), Nicolás Bentancur, (Universidad de la República de Uruguay), Robert Verhine (UFBA - Brasil), Rosana Cruz (UFPI - Brasil), Rubens Barbosa Camargo (USP - Brasil), Sebastián Donoso Díaz (Universidad de Talca - Chile), TheresaAdrião (UNICAMP - Brasil), Vera Peroni (UFRGS - Brasil).

Créditos e Agradecimentos:

Revisão de Língua Portuguesa, Abstract e Resumen: PROGRAMA DE APOIO ÀS PUBLICAÇõES CIENTÍFICAS PERIÓDICAS DA UFPR

Arte e diagramação: TIAGO TAVARES (thiagotav@gmail.com)

Jornal de Políticas Educacionais

Universidade Federal do Paraná

Setor de Educação

Núcleo de Políticas Educacionais - NuPE/UFPR

Avenida Sete de Setembro, 2645

2 o andar, Sala 213

80.230-010 - Curitiba - PR - Brasil

Tel.: 41-3535-6264

jpe@ufpr.br

http://revistas.ufpr.br/jpe 